\title{
Defining the Conditions of Forming Students Motivation to Movement Activity
}

\author{
Olena Lutsenko ${ }^{1, *}$, Gregory Lucenko ${ }^{2}$, Maryna Khrolenko ${ }^{3}$, Olesya Mehem ${ }^{4}$ \\ ${ }^{1}$ Department of Theory and Methodics of Teaching Natural Sciences, Oleksandr Dovzhenko Hlukhiv National Pedagogical University, \\ Ukraine \\ ${ }^{2}$ Doctor of Pedagogical Science, Vice-rector, Oleksandr Dovzhenko Hlukhiv National Pedagogical University, Ukraine \\ ${ }^{3}$ Faculty of Natural and Physical and Mathematical Education, Oleksandr Dovzhenko Hlukhiv National Pedagogical University, \\ Ukraine \\ ${ }^{4}$ Department of Biology and Fundamentals of Agriculture, Oleksandr Dovzhenko Hlukhiv National Pedagogical University, Ukraine
}

Received May 26, 2020; Revised July 13, 2020; Accepted July 29, 2020

\section{Cite This Paper in the following Citation Styles}

(a): [1] Olena Lutsenko, Gregory Lucenko, Maryna Khrolenko, Olesya Mehem , "Defining the Conditions of Forming Students Motivation to Movement Activity," International Journal of Human Movement and Sports Sciences, Vol. 8, No. 4, pp. 117 - 123, 2020. DOI: 10.13189/saj.2020.080403.

(b): Olena Lutsenko, Gregory Lucenko, Maryna Khrolenko, Olesya Mehem (2020). Defining the Conditions of Forming Students Motivation to Movement Activity. International Journal of Human Movement and Sports Sciences, 8(4), 117 123. DOI: $10.13189 /$ saj.2020.080403.

Copyright $@ 2020$ by authors, all rights reserved. Authors agree that this article remains permanently open access under the terms of the Creative Commons Attribution License 4.0 International License

\begin{abstract}
The purpose of our study was to determine the level of motor activity in students, as well as to promote the formation of motivation to engage in physical sports. University students ( $\mathrm{n}=54$, age $17-21$ years) divided into 2 groups according to physical activity and sex. For the research, the self-developed questionnaire was used and processed by the statistical method with determining the relative parity indexes. The results of the research allowed studying the student's attitude to physical education in universities and independently, to assess the subjective state of health of different grade students, the reasons for abandoning physical exercises. The results are consistent with satisfaction with classes at university and the reasons for abandoning additional classes. Girls prefer classes of non-traditional types of $\mathrm{PE}$ that are not included in the program of the higher educational institutions and require significant financial investments that students cannot afford. Male students prefer sports games, and although they are included in the program, there are no free sections. Students pay little attention to physical activity, thus they do not have the formed need for independent exercises in physical culture, and most of them prefer to be engaged in non-traditional health-improving forms of physical culture. The amount of motor activity physical education classes showed a clear training effect and can be considered as one of the benchmarks of the compensatory role of classes in
\end{abstract}

eliminating hypodynamic. Also in the article, the authors consider motivation as a dynamic process of continuous choice and decision-making, based on weighing behavioral alternatives, explaining the purposefulness, organization, and sustainability of holistic measures to achieve a certain goal acts as an incentive to act with a certain motive.

Keywords Students, Motivation, Movement Activity, Hypodynamic, Health

\section{Introduction}

The existing system of higher education puts forward modern requirements for the health, physical, and mental capacity of student youth. After all, strengthening health and increasing the level of physical fitness are important conditions for ensuring the comprehensive and harmonious development of individuals, maintaining the ability to work in the educational process of student youth. The importance of these factors is constantly updated in connection with the increasing load on the mental and emotional spheres in the learning process.

Preserving and strengthening the health of students during their studies and preparing them for professional 
activities is an important component of higher education and a guarantee of the creative longevity of future professionals. In the set of social activities that ensure the health of students, a certain place belongs to physical culture, which ensures high educational and employment of students and their high efficiency after graduation.

Young people are the future of society, but they are also very present. About half of the world's population is under 20 years old. According to statistics and experiences of young people serving the WYR (World Youth Report), adolescents who are healthy and happy have a better opportunity to contribute to their communities as young citizens, despite major changes in the world, they must follow.

The problem of forming, strengthening, and maintaining individual health remains relevant today. There are different approaches to solving it. At the same time, a special place for maintaining and promoting health belongs to physical activity. However, in the presence of publications on the importance of exercise for humans to date, they do not clearly substantiate the types and levels of daily physical activity to maintain functionality compatible with optimal health.

The formed substantiation of the action, actions is a motive. It is the inner state of the individual that determines and directs his actions at every moment of time.

The motivation for physical activity - a special state of personality, aimed at achieving the optimal level of physical fitness and efficiency.

The process of forming an interest in physical culture and sports is not a one-step, but a multi-stage process: from the first basic hygienic knowledge and skills (in childhood) to deep psychophysiological knowledge of the theory and methods of physical education and intensive sports.

Motivational and value component reflects the active-positive emotional attitude to physical culture, forms the need for it, the system of knowledge, interests, motives, and beliefs, volitional efforts aimed at practical and cognitive activities. Motivation is the main component for the successful completion of any activity.

\section{Literature Review}

The existing system of higher education sets high demands on the health, physical, and mental capacity of student youth.

Strengthening health and improving the level of physical fitness are important conditions for ensuring the complex and harmonious development of the individual, maintaining work efficiency in the students' educational process. The significance of these factors is constantly increasing due to the increased demands on the learning process, increased mental and emotional stress.

To some extent, this has been reflected in researchers' research into the use of exercise throughout their lives, enhancing the potential of a youth movement, and maintaining overall health. (Ahmadi, Pfeiffer, \& Trost, 2020).

A healthy lifestyle contributes to recovering, maintaining, and developing reserve capacities of the body in which the compulsory component is movement activity (Lutsenko, 2017).

The problem of forming, strengthening, and preserving individual health remains relevant nowadays. Different approaches are used for solving it. This motor activity takes a special place to maintain and strengthen health (Ennis, 2017, Lawler, Heary, Nixon, 2017, Sheeran, Conner, 2017). However, in spite of the existence of a large number of publications about the significance of physical exercise for the person, there is still no clear justification for the types and levels of daily motor activity necessary to maintain the functional capabilities compatible with optimal health.

In recent years there has been an increase in the number of students who have serious deviations in their health (Hannan, Moffitt, Neumann, Thomas, 2015, Jones, Karageorghis, Lane, Bishop, 2017, Ocampo-Mascaró, Silva-Salazar, da Costa-Bullón, 2015, Peng, Pfeiffer, Winn, Lin, Suton, 2015, Strohacker, Galárraga, Emerson, Fricchione, Lohse, Williams, 2015). These deviations, as a rule, arise in early childhood $-40 \%$ of children are born with deviations, only $10-14 \%$ of children start school almost healthy. Only $16 \%$ of students are enrolled in higher educational establishments being healthy. Therefore students' health is one of the important subjects of study for many researchers.

Keeping and strengthening the students' health during the period of studying at higher education institutions and training them for their professional activity is an important basis for higher education and the creative longevity of future specialists. In the complex of social activities providing health care for students, a certain place belongs to the physical culture, which ensures high educational and labor activity of students and their high efficiency after graduating from the university (Chernii et al., 2020).

The main component for successful performing any activity, including physical education and sports, is motivation. Motivation is the process of forming and justifying the intention to do or not to do something. The motivation for physical activity is a special state of the personality, aimed at achieving the optimal level of physical readiness and ability to work (Murray et al., 2020).

The purpose of our study was to determine the level of motor activity in students, as well as to promote the formation of motivation to engage in physical sports.

\section{Methodology of the Study}

\subsection{Participants}

The research was conducted based on the Faculty of Natural and Physical and Mathematical Education of 
Oleksandr Dovzhenko Hlukhiv National Pedagogical University.

54 students including 30 female students and 24 male students were divided into 2 groups:

$\mathrm{I}-$ do not go in for certain sports $(\mathrm{n}=32)$

II - sports game $(n=22)$

The study was conducted in compliance with the basic bioethical provisions of the Council of Europe Convention on Human Rights and Biomedicine (of April 4. 1997), Helsinki declaration of the World medical association on ethical principles of conducting scientific medical investigations with participation of humans (1994-2008), and the Order of the Ministry of Health Protection of Ukraine № 690 of September 23. 2009.

We analyzed the use of the system of events in the amount of 9-12 hours of weekly work aimed at compensating for the deficit of students motor activity of the main medical group, of which 20 were engaged in physical education at the $1^{\text {st }}$ and $2^{\text {nd }}$ grades in the amount of 4 hours per week, and $173^{\text {rd }}$ grade students who exercised 2 hours a week.

The system of events included: a) morning hygiene exercises of 20-30 minutes; outdoor walks of 20-30 minutes and 2 hours walk at the speed of 5-6 km per hour on days off; b) intensifying training sessions on physical education using natural kinds of movements (running, jumping, jumping exercises, games and game exercises, races) which ensure students active involving into motor activity with the necessary emotional background.

\subsection{Methods}

To determine the level of health of students with different levels of motor activity the complex evaluation system of H.L. Apanasenko was applied (Apanasenko, 1992).

Developing the concept of "health quantity" (Apanasenko, 1992) allows us to create a scale for assessing its reserves, suitable for applying during mass surveys. H.L. Apanasenko (1992) justified the methodology of a quantitative assessment of physical health which is based on the existing correlation between the level of development of maximum aerobic capacity on the one hand, and the volume of physiological reserves and the degree of manifestation of the syndrome of the economizing functions in the state of rest and metered physical loads on the other hand. The choice of this method is due to the fact that it enables us to determine in a complex way the functional state of the body according to indicators of the cardiorespiratory and muscular system, which are formalized in quantitative units (points) and are associated with the level of individual health. This technique consists of defining anthropometric and functional indicators and indices. To conduct the research we developed a questionnaire.

The questionnaire is represented by 16 questions to the respondent. All questions directly or indirectly relate to students' understanding of health, motivation for physical education, physical activity.

For example:

- How do you assess your health?

- Do you have bad habits?

- What is your level of awareness about the impact of physical culture on the body and human health?

- To what extent do physical education classes in the educational institution meet your needs?

- Do you do extra physical education?

- What additional health-improving activities do you prefer?

- What is your dominant motivation in physical education?

Each question had a list of answers and allowed us to assess the level of awareness of students and the opportunity for us to process these questionnaires.

The data obtained as a result of the questionnaire were processed by the statistical method of determining the relative proportions. It involves analyzing the results of the study to determine the percentage proportion between the parts and the whole. The following formula is used for calculating:

$$
P_{\%}=\frac{m}{n} \times 100 \%,
$$

where $\mathrm{P}$ - the indicator of the relative part of the percent.

$\mathrm{m}$ - number of respondents choosing one or another variant of the answer.

$\mathrm{n}$ - sample size.

The results of the research allowed studying the students' attitude to physical education in universities and independently, to assess the subjective state of health of students of different grades, the reasons for abandoning the physical education classes.

\subsection{Statistical Processing}

The data were processed by generally accepted statistical methods using the personal computer and the program Statistica 6.0. As the evaluation of each surveyed was based on the points scale we used later not the arithmetic average of the points scored, but the median. For comparison non-parametric methods of analysis were used, in particular the Wilcoxon test.

\section{Study Results}

The survey was attended by 54 students among whom 9 persons were 1st-grade students, 9 - 2nd grade, 10 - 3rd grade, 19 - 4th grade. In the process of filling 7 questionnaires were spoiled.

$51 \%$ of respondents live in the dormitory, $40 \%$ live at home, and $9 \%$ rent an apartment. Most 1st grade students 
subjectively assess their health as good - 67\%, others consider their health to be normal. Among the 2nd grade students, the situation is the reverse - $33 \%$ of them consider their health to be good, the rest - normal. $14 \%$ of 3rd-grade students rated their health as bad, $57 \%$ as normal, and $29 \%$ as good. Among the 4 th grade, $32 \%$ have the answers "normal" and "good" and 36\% rated their health as excellent (Figure 1).

The question "Do you have bad habits?" was answered negatively by $33 \%$ of freshmen, $67 \%$ of second-grade students, $57 \%$ of third-grade students, $53 \%$ of fourth-grade students. The rest of the students answered, "Yes, I smoke/drink". In our opinion, the growth of negative responses compared to the first grade is due to the fact that students begin to realize the importance of a healthy lifestyle, learn more about the importance of abandoning bad habits. The next question concerned nutrition. It included the possibility of choosing several answers (or, possibly, none). $34 \%$ of respondents named their nutrition as proper and $19 \%$ as balanced. $32 \%$ of students eat at regular hours; $47 \%$ believe that their food is rational.

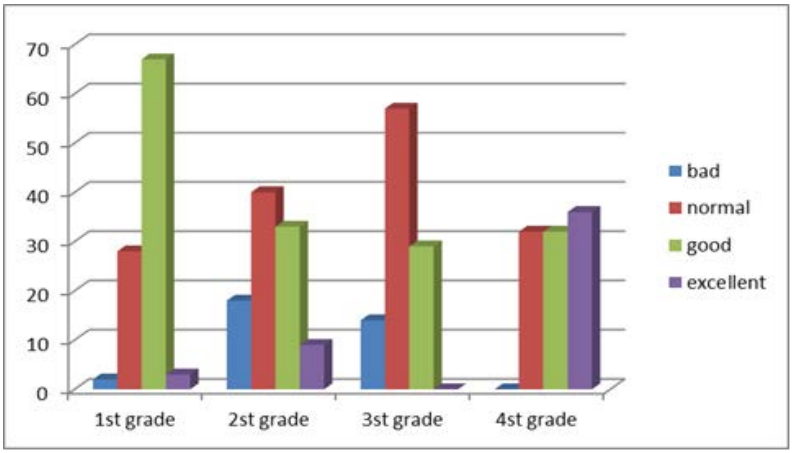

Figure 1. Students subjective assessment of own health
In the question of sources and degrees of awareness of the influence of physical education (PE) on the human body, which also provided the possibility of several answers options, $67 \%$ of first-grade students pointed that they were aware of the influence of PE on the human body from specialized literature, $17 \%$ named teachers. The latter datum is due, above all, to the lack of coverage of issues of physical education in the university. The interested teens have to seek information in additional literature. All second-grade students pointed out that the teachers informed them about the significance of the PE, and $11 \%$ also pointed out the information from the specialized literature. In the third grade $86 \%$ of students pointed out the information from the teachers and $29 \%$ were familiar with the literature. In the fourth grade $74 \%$ of students are aware of the importance of PE for a person from teachers, and 24\% from specialized literature. Other sources were also mentioned, including television, periodicals, and personal experience of respondents (Figure 2; Figure 3).

$21 \%$ of respondents noted that they are fully satisfied with PE classes in the university, but the overwhelming majority $-64 \%$ are only partly satisfied. $17 \%$ of freshmen are regularly engaged in PE in their free time, 22\% second-grade students, $29 \%$ of third-grade students, $26 \%$ of the fourth-grade students. $33 \%$ of students of the first grade are engaged in independent exercising, $44 \%$ of the second-grade students, $43 \%$ of the third-grade students, $42 \%$ of the fourth-grade students. $33 \%$ of freshmen do not see the necessity of classes for themselves, as well as $17 \%$ of third-grade students and $11 \%$ of fourth-grade students. The rest do not go in for exercises due to subjective reasons being aware though of the importance of exercises. Such results confirm the dissatisfaction of students with $\mathrm{PE}$ classes at universities: most prefer to engage themselves independently.

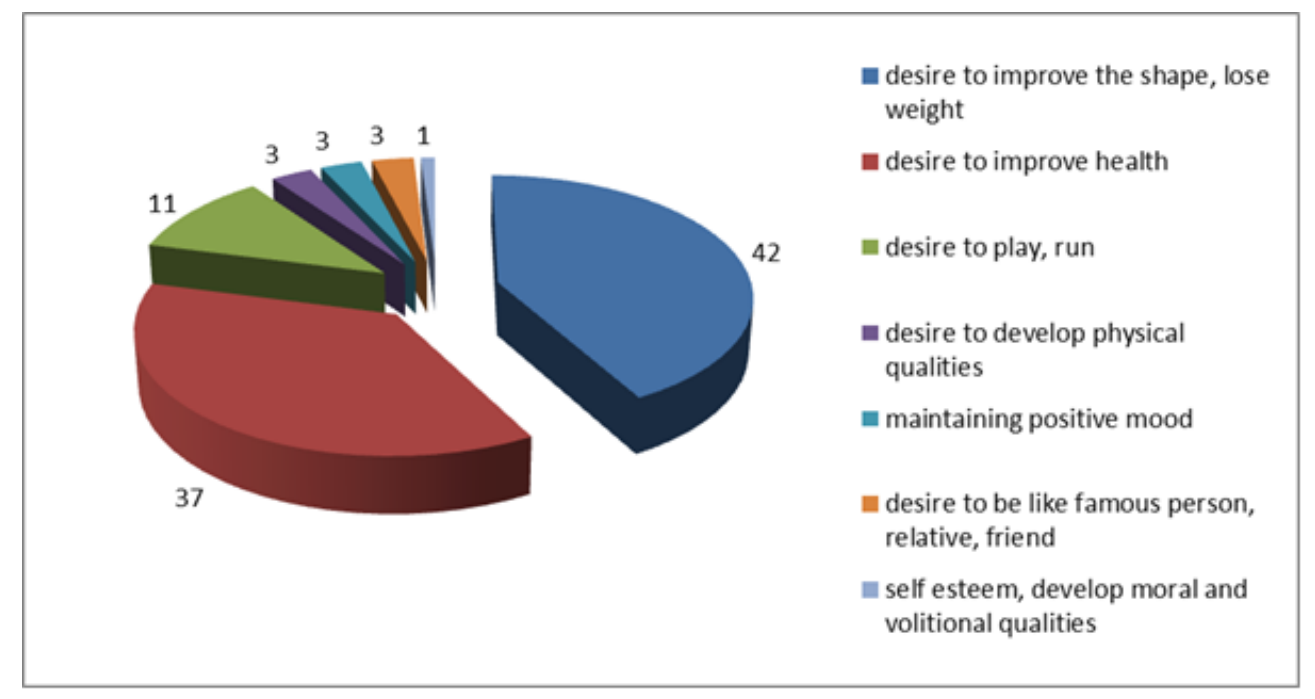

Figure 2. Female students dominating motivations 


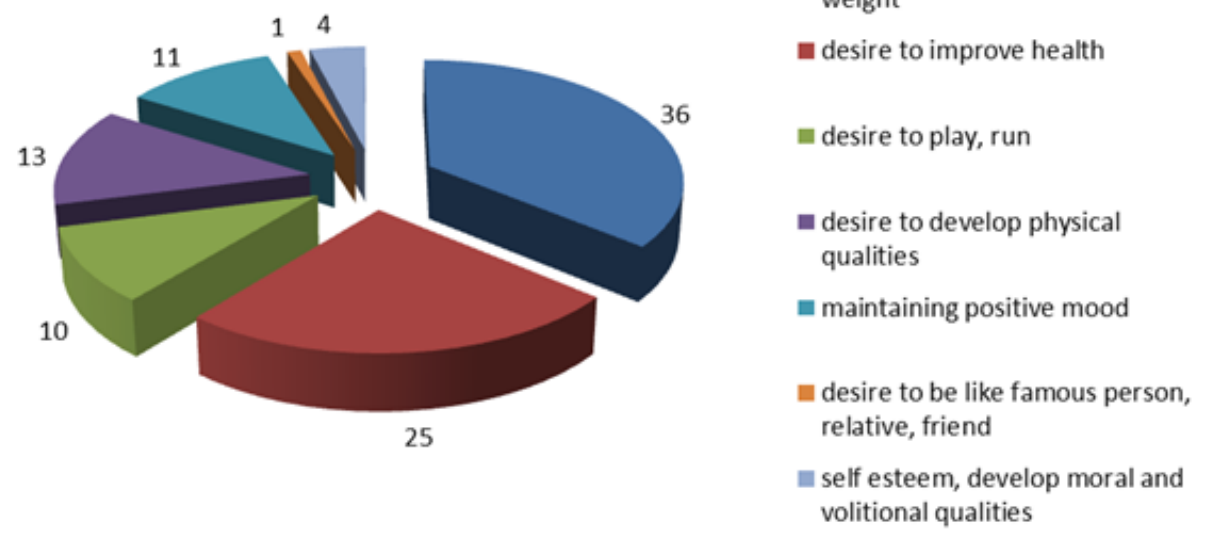

Figure 3. Male students dominating motivations

Respondents who do not go in for exercises systematically noted mostly lack of funds and logistics, fatigue, unwillingness to exercise (23\%) among the reasons that hinder exercising. To the question "What kind of additional recreational activities do you prefer?" (the question also suggested the possibility of choosing among several answers), most girls responded that they preferred non-traditional types of PE classes (63\%). Male students prefer sports games (54\%).

The results of this question are consistent with satisfaction with classes at university and the reasons for abandoning additional classes. Girls prefer classes of non-traditional types of PE that are not included in the program of higher educational institutions and require significant financial investments that students cannot afford. Male students prefer sports games, although they are included in the program, there are no free sections.

The dominant motivation in physical exercising among girls was the desire to improve the shape, posture, and lose weight (47\%); of the secondary motivations, the desire to strengthen health has the leading place (also 47\%). Among male students, there is also a motivation for improving the shape, muscle buildup (36\%). The secondary motive was the lack of motor activity and the desire to move (54\%). It should be noted that among the secondary motivations only two issues were proposed to be chosen.

The majority of students responded "positively" (67\%) and "more positively" (27\%) to the question about the attitude toward extra-curricular activities, which suggests that students want to expand their motor skills through new, non-standard forms of physical education. Students negatively related to the trips were absent at all.

After analyzing the questionnaires of respondents, we have developed guidelines for motivation to the motor activity of students in accordance with the studied faculty of the educational institution. They were discussed at a meeting of the faculty council and had the status of "implementation".

These recommendations include theoretical and practical parts. The theoretical part is devoted to the conceptual apparatus - what is health, motor mode, etc. The practical part is devoted to a set of selected exercises for students for all muscle groups that lead a sedentary lifestyle. Also contain indications and contraindications to various sports, gymnastics, etc.

\section{Discussion}

Having analyzed the results of our study, we clearly realized that physical culture in modern conditions acts as one of the important components of the formation of personality culture. An important factor in improving the effectiveness of the physical education of students, which will form in them a lasting interest and a conscious need for a healthy lifestyle.

Having studied the results of the questionnaire, we believe that the problem of motivation to study for physical self-improvement of students is important, which is currently largely underdeveloped. Therefore, the ways of forming the need for active motor activity is a task of paramount importance.

On the basis of studying and processing the research data of the other authors (Bouchard, 2012, Kipp, 2017, Lutsenko, Kovalenko, 2017) and according to the results of our study, it was found that the motivational interest of students of different institutions of higher education (non-sport specialties) in physical education classes is extremely low (Cline, Gammage, 2015, Han, Gabriel, Kohl, 2017, Zarei, Memari, Moshayedi, Mosayebi, Mansournia, Khoo, Morris, 2016). It directly affects health and disability. However, many students are engaged in physical education outside the university, and others would like to be engaged, but they do not have such an opportunity, 
which testifies to poor organizing physical education at the university not meeting the interests and needs of student youth. and therefore cannot support their motivational interest. Having studied the students' preferences and wishes, we concluded that there was a need to make changes and improvements in organizing physical education classes in order to increase motivation for them (Ahn, Fedewa, 2011, Butt, Weinberg, Breckon, Claytor, 2011, Dimmock, Gagné, Proud, Howle, Rebar, Jackson, 2016).First of all it should be noted that motivational orientation and interests in the sphere of physical culture and sports among boys and girls are different. In this regard, one should deal with them separately like it is obligatory in classes for senior pupils (Amis, Wright, Dyson, Vardaman, Ferry, 2012). For them, it should be planned not only to have different standards, but also different structure of classes, and therefore the choice of subject is not limited to a certain chosen sport because of the lack of a strict sports orientation of specialization, then it is also possible to choose the types of exercises according to interests, the variety of forms, means and methods of organizing classes are also possible (Biddle, et al., 2019, Keller, Gellert, Knoll, Schneider, Ernsting, 2016). Among the other things, respondents showed their great interest in such forms of organizing PE classes as hiking and tourist festivals. They have a complex effect on the body, promote the development of physical, mental, and moral-volitional qualities, endurance, mutual help (Rebar, Dimmock, Jackson, Rhodes, Kates, Starling, Vandelanotte, 2016). They also affect the aesthetic sphere of the student, form an idea of the beauty, promote developing the values of a healthy lifestyle. In this regard, they make an excellent alternative to traditional physical education classes and stimulate interest in physical culture and active lifestyle.

\section{Conclusions}

1. The complex of pedagogical and recreational activities used in the experiment provided the steady compensation for hypodynamia $(79-84 \%$ of the required physical activity) which is estimated to be satisfactory for this student's age group.

2. The amount of motor activity physical education classes showed a clear training effect and can be considered as one of the benchmarks of the compensatory role of classes in eliminating hypodynamy.

3. According to the research data, modern youth pay not enough attention to physical activity, only $6.5-7.5 \%$ of respondents prefer to spend their leisure time in physical exercise. Students have not formed the need for independent classes in physical education. Of the aforementioned motives influencing young people, the vast majority of studies, including our one, indicate aesthetic reasons as prevailing - desire to develop physical qualities, improve posture, shape: $36 \%$ of males and $47 \%$ of females.

4. We consider motivation as a dynamic process of continuous choice and decision-making based on the weighing of behavioral alternatives, which explain the purposefulness of action, organization, and sustainability of holistic activities aimed at achieving a certain goal acts as an incentive to act with a certain motive. The motivation of students to focus on physical education is not sufficiently reflected in the system of physical education in the educational institution or does not meet the needs of young people. To effectively involve students in physical activity, we suggest paying attention to the motivation for such activity, the benefits of choosing forms of classes, and their content.

\section{Conflicts of Interest}

Authors declare no conflict of interest.

\section{REFERENCES}

[1] Ahmadi, M. N., Pfeiffer, K. A., \& Trost, S. G. (2020). Physical Activity Classification in Youth Using Raw Accelerometer Data from the Hip. Measurement in Physical Education and Exercise Science, 1-7. https://doi: 10.1080/1091367X.2020.1716768.

[2] Ahn, S., \& Fedewa, A. (2011). A meta-analysis of the relationship between children's physical activity and mental health. Journal of Pediatric Psychology, 36 (4), 385-397.

[3] Amis, J., Wright, P., Dyson, B., Vardaman, J., \& Ferry, H. (2012). Implementing childhood obesity policy in a new educational environment: the cases of Mississippi And Tennessee. American Journal of Public Health, 102 (7), 1406-1413. https://doi: 10.2105/AJPH.2011.300414

[4] Apanasenko, G. (1992) The evolution of bioenergetics and human health Evolyutsiya bioenergetiki $i$ zdorovye cheloveka, SPb.: MGP «Petropolis», 123.

[5] Biddle, S. J., Ciaccioni, S., Thomas, G., \& Vergeer, I. (2019). Physical activity and mental health in children and adolescents: An updated review of reviews and an analysis of causality. Psychology of Sport and Exercise, 42, 146-155. https://doi: 10.1016/j.psychsport.2018.08.011.

[6] Bouchard, C. (2012). Genomic predictors of trainability. Experimental Physiology, 97(3), 347-352. https://doi: 10.1113/expphysiol.2011.058735

[7] Butt, J., Weinberg, R., Breckon, J., \& Claytor, R. (2011). Adolescent physical activity participation and motivational determinants across gender, age, and race. Journal of Physical Activity and Health, 8(8), 1074-1083. https://doi: 10.1123/jpah.8.8.1074.

[8] Chernii, V., Shevchenko, O., Nievorova, O., Melnyk, A., 
Kramarenko, A., Nikonenko, T. (2020). Development of Professionally Important Physical Qualities in Engineering Students. Revista Romaneasca Pentru Educatie Multidimensionala, 12(1), 93-105. https://doi: 10.18662/rrem/12.1sup1/225.

[9] Cline, L., \& Gammage, K. (2016). "If you don't have anything nice to say, then don't say anything at all": positive appearance-related commentary and physical activity. Journal Phys Act Health, 13(4), 366-70. https://doi: 10.1123/jpah.2015-0333.

[10] Dimmock, J., Gagné, M., Proud, L., Howle, T., Rebar, A., \& Jackson, B. (2016). An Exercise in Resistance: Inoculation Messaging as a Strategy for Protecting Motivation During a Monotonous and Controlling Exercise Class. Journal Of Sport \& Exercise Psychology, 38(6), 567-578. https://doi: 10.1123/jsep.2016-0146.

[11] Ennis, C. (2017). Educating Students for a Lifetime of Physical Activity: Enhancing Mindfulness, Motivation, and Meaning. Research Quarterly For Exercise And Sport, 88(3), 241-250. https://doi: 10.1080/02701367.2017.1342495.

[12] Han, H., Gabriel, K. P., \& Kohl, H. (2017). Application of the transtheoretical model to sedentary behaviors and its association with physical activity status. PLoS One, 12(4), e0176330. https://doi: 10.1371/journal.pone.0176330.

[13] Hannan, T., Moffitt, R., Neumann, D., \& Thomas, P. (2015). Applying the theory of planned behavior to physical activity: the moderating role of mental toughness. Journal Of Sport \& Exercise Psychology, 37(5), 514-22. https://doi: 10.1123/jsep.2015-0074.

[14] Jones, L., Karageorghis, C., Lane, A., \& Bishop, D. (2017). The influence of motivation and attentional style on affective, cognitive, and behavioral outcomes of an exercise class. Scandinavian Journal Of Medicine \& Science In Sports, 27(1), 124-135. https://doi: 10.1111/sms.12577.

[15] Keller, J., Gellert, P., Knoll, N., Schneider, M., \& Ernsting A. (2016). Self-efficacy and planning as predictors of physical activity in the context of workplace health promotion. Applied Psychology-Health And Well Being, 8(3), 301-321. https://doi: 10.1111/aphw.12073.

[16] Kipp, L. (2017). Psychosocial Aspects of Youth Physical Activity. Pediatric Exercise Science, 29(1), 35-38. https://doi: 10.1123/pes.2017-0005.

[17] Lawler, M., Heary, C., \& Nixon, E. (2017). Variations in adolescents' motivational characteristics across gender and physical activity patterns: A latent class analysis approach. Public Health, 17(1), 661. https://doi: 10.1186/s12889-017-4677-x.
[18] Lutsenko, O., \& Kovalenko, S. (2017). Blood pressure and hemodynamics: Mayer waves in different phases of ovarian and menstrual cycle in women. Physiological research, 66, 235-240. https://doi: 10.33549/physiolres.933313

[19] Lutsenko, O. (2017) Morphological factors influence on young women arterial pressure levels. Clin. Pract. United Kingdom, 14(5), 334-337.

[20] Murray, J. M., French, D. P., Kee, F., Gough, A., Tang, J., \& Hunter, R. F. (2020). Mechanisms of physical activity behavior change in an incentive-based intervention: Mediation analysis. Health Psychology, 39(4), 281-297. https://doi: 10.1037/hea0000849.

[21] Ocampo-Mascaró, J., Silva-Salazar, V., \& da Costa-Bullón, A. (2015). Correlation between knowledge about the consequences of obesity and physical activity levels among university students. Medwave, 15(11), e6329. https://doi: 10.5867/medwave.2015.11.6329.

[22] Peng, W., Pfeiffer, K., Winn, B., Lin, J., \& Suton, D. (2015). A pilot randomized, controlled trial of an active video game physical activity intervention. Health Psychology, 34, 1229-39. https://doi: 10.1037/hea0000302.

[23] Rebar, A., Dimmock, J., Jackson, B., Rhodes, R., Kates, A., Starling, J., \& Vandelanotte, C. (2016). A systematic review of the effects of non-conscious regulatory processes in physical activity. Health Psychology Review, 10(4), 395-407. https://doi: 10.1080/17437199.2016.1183505

[24] Sevil, J., Práxedes, A., Abarca-Sos, A., Del Villar, F., \& García-González, L. (2016.) Levels of physical activity, motivation and barriers to participation in university students. Journal Of Sports Medicine And Physical Fitness, 56(10), 1239-1248. Epub 2015 Nov 10.

[25] Sheeran, P., Conner M. (2017) Improving the translation of intentions into health actions: The role of motivational coherence. Health Psychology, 36(11), 1065-1073. https://doi: 10.1037/hea0000553.

[26] Strohacker, K., Galárraga, O., Emerson, J., Fricchione, S., Lohse, M., Williames, D. (2015) Impact of small monetary incentives on exercise in university students. American Journal Of Health Behavior, 39(6), 779-86. https://doi: 10.5993/AJHB.39.6.5.

[27] Zarei, S., Memari, A., Moshayedi, P., Mosayebi, F., Mansournia, M., Khoo, S., \& Morris, T. (2016). Psychometric properties of physical activity and leisure motivation scale in farsi: an international collaborative project on motivation for physical activity and leisure. Archives Of Iranian Medicine, 19(10), 704-711. 